\title{
Density analysis of Flickr data as a proxy to reveal the intensity of tourism activity in Borobudur
}

\section{Totok Wibowo, Achmad Rofi'i, Nur Sulistyaningrum}

Totok W. Wibowo, Achmad Rofi'i, Nur A. Sulistyaningrum, "Density analysis of Flickr data as a proxy to reveal the intensity of tourism activity in Borobudur," Proc. SPIE 11311, Sixth Geoinformation Science Symposium, 113110F (21 November 2019); doi: 10.1117/12.2549040

SPIE Event: Sixth Geoinformation Science Symposium, 2019, Yogyakarta, Indonesia 


\title{
Density Analysis of Flickr Data as a Proxy to Reveal the Intensity of Tourism Activity in Borobudur
}

\author{
Totok W. Wibowo*a, Achmad Rofi' ${ }^{\mathrm{a}}$, Nur A. Sulistyaningrum ${ }^{\mathrm{a}}$ \\ ${ }^{a}$ Department of Geographic Information Science, Faculty of Geography, Universitas Gadjah Mada, \\ Bulaksumur Yogyakarta 55281. *Corresponding author: totok.wahyu@ugm.ac.id
}

\begin{abstract}
Indonesia has many cultural heritages that attracts not only local tourist but also a foreigner. The most renowned site for cultural tourism is Borobudur, that attracts many tourists. It also included as one of the seven cultural wonders in the world. Tourism activity cannot be separated from photography since the visitors would want to have memories of the locations. Involuntary Geographic Information (iVGI) is one of the new sources of information that can be used to analyze the pattern of human activities spatially. This research explores Flickr data as an example of using photo-based iVGI data for hotspot analysis of human activities in cultural tourism objects. Each photo in Flickr's database located in Borobudur can be assumed as an activity log since Flickr allowed the user to add geotagged photos. Though a data cleaning process must be done to filter irrelevant data. Point Density was employed in this study to explore photo distribution in the study area. The density will act as an indicator that an area is more frequently visited by visitors. Besides, Zonation of Borobudur Region data was used to justify the density and the zone designated by the official document. The results of the study show that the peak of photography activity occurs at $13 \mathrm{pm}$ and area arround the Stupa of Borobudur Temple has attracted visitor in undertaking photo shoot activity.
\end{abstract}

Keywords: iVGI, Borobudur, Flickr, Spatiotemporal

\section{INTRODUCTION}

Spatial studies require geographically referenced data, which can be represented by points, lines, and polygons. Traditionally, spatial data can be obtained using geospatial data sources, such as satellite imagery, secondary data, and direct surveys. Current technological developments allow people to upload their activities through social media platforms. Social media data uploaded by users can be plotted on the map, along with the widespread use of communication devices equipped with GPS receivers. Fischer [1] introduced the term Involuntary Geographic Information (iVGI) to refer to spatial data originating from social media users. In this case, the main objective of the upload is not always the same as those of data usage. The term iVGI is the development of a Volunteered Geographic Information (VGI) conceptualized by Goodchild [2], where user uploads are in line with the purpose of data usage.

Diverse data uploads of social media users bring challenges in its management [3]. The data must be processed first to ensure the level of relevance to the analysis to be carried out. Many researchers applied filters to obtain relevant data to suit their needs [4]-[6]. Of course, to be used as a spatial data source, users must add location information to the data they uploaded.

Flickr is one of the photo-sharing services that allow a user to upload geotagged photos. Created in 2004, Flickr is estimated to have more than 90 million users in 2017. Photos from social media uploads are certainly very diverse. Visitor activity in a tourist attraction is an interesting topic in social media study. Tourists surely want to capture the moment of their vacation in the tourist sites. Some even upload photos taken into their social media accounts. Thus, geotagged photo found around tourist objects can be assumed to be a record of activities at tourist sites [7].

Mapping tourist activities in a tourist attraction could provide support for determining development priorities. Photogenic spots are currently commonly used as one of the allurements in many tourist attractions. Photograph dissemination through social media has also an impact on the increasing popularity of tourism objects that have emerged lately. Based on this fact, the determination of photographic activities in a tourist attraction could utilize historical data on geotagged photos taken by tourists [8], [9]. Furthermore, the result of the analysis could provide insights into tourist attraction's management.

Sixth Geoinformation Science Symposium, edited by Sandy Budi Wibowo, Andi B. Rimba

Stuart Phinn, Ammar A. Aziz, Proc. of SPIE, Vol. 11311, 113110F · ( 2019 SPIE

CCC code: $0277-786 \mathrm{X} / 19 / \$ 21 \cdot$ doi: $10.1117 / 12.2549040$ 


\section{STUDY AREA}

This study was conducted at the Borobudur Temple Compound, which is one of Indonesia's leading tourist locations and listed as one of UNESCO's cultural heritage (Figure 1). Based on the authority data there were 3,135,292 local and foreign tourists throughout 2017, the highest among other tourist attractions in Central Java Province [10]. Administratively, Borobudur Temple Compound belongs to Magelang Regency Area. Magelang city is the nearest city from Borobudur, but a lot of Tourist also come from the Special Region of Yogyakarta. Around Borobudur temple, there are also Mendut temples and Pawon temples, which form a straight line called Borobudur Temple Compound. On the west side of Borobudur, there is a relatively new tourist attraction called Gereja Ayam Rhema Hill, which was recently famous thanks to social media.

Based on the zoning prepared by JICA, there are five zones for heritage management [11]. Zone 1 and zone 2, is the complex of Borobudur Temple which functions for the Archaeological Environment Preservation and Archaeological Park. Meanwhile, the other three zones serve to preserve historical scenery. In the zoning are also included several other cultural objects, for example, Dipan Site, Brongsongan Site, and Mendut Kerkhoff.

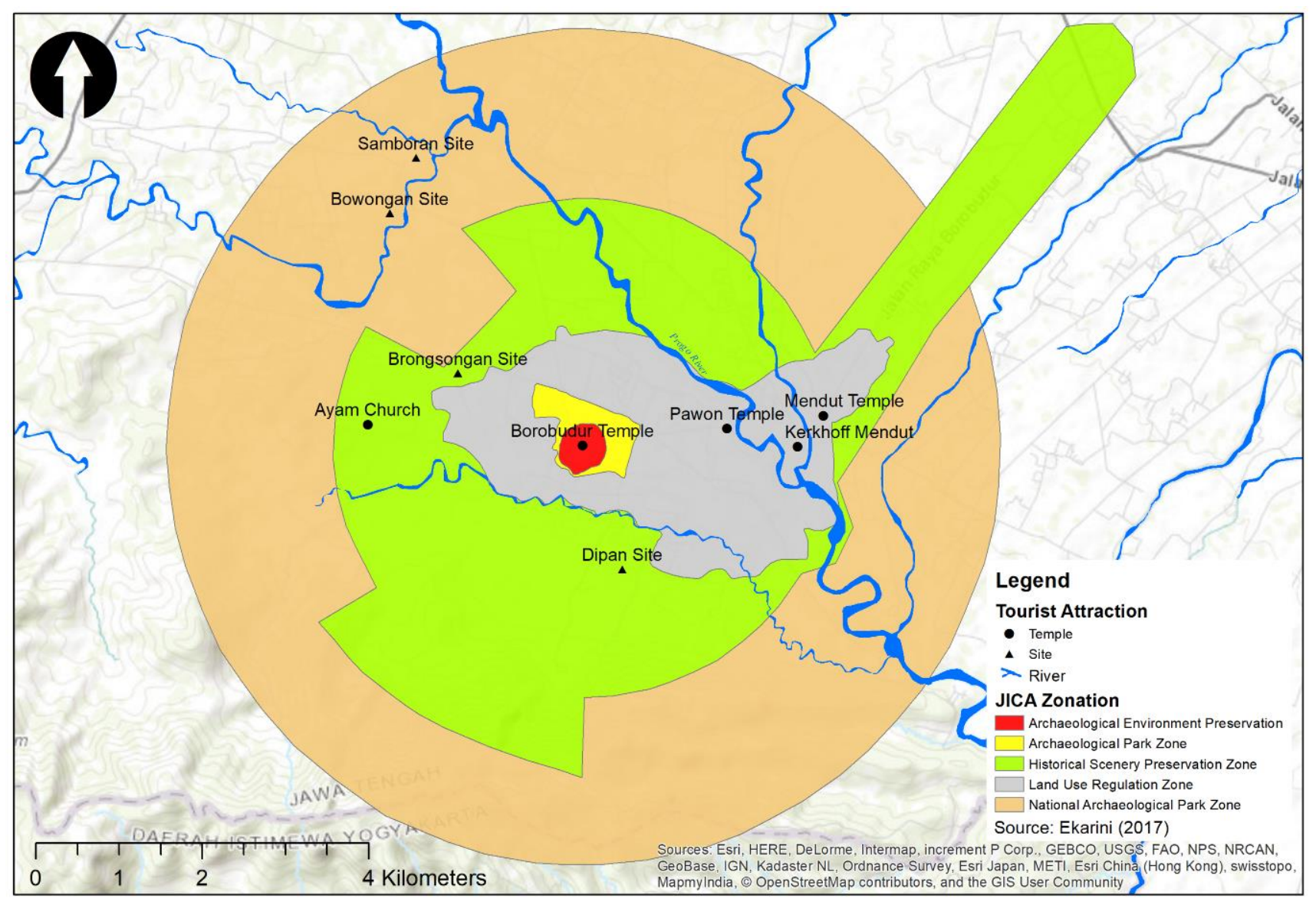

Figure 1. Study area, located in Borobudur Temple and its vicinity

\section{METHODS}

\subsection{Data Pre-Processing}

The Flickr API is used to obtain geotagged photo metadata around the study area. In the metadata listed some information, such as title, tag, accuracy, date, latitude, and longitude. There is a time limit that applies to the data, which only uses data from 2004 to 2018 . The time limitation is carried out to get the whole data per year as input in spatiotemporal data analysis. Overall there are 4,631 unfiltered Flickr photos in the study area (Figure 2). 


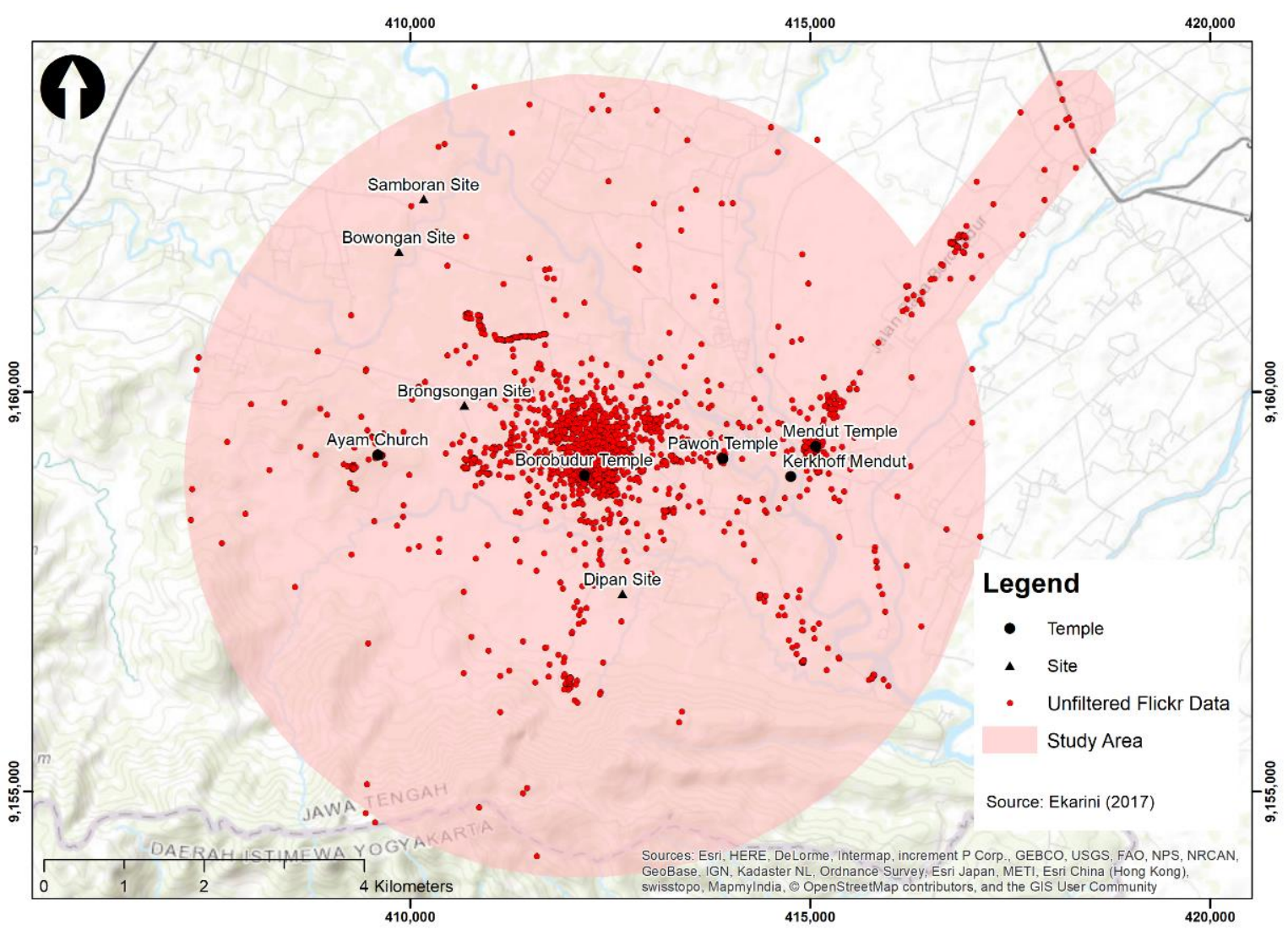

Figure 2. Unfiltered Flickr geotagged photos locations in the study area

Data filtering is the first processing step applied once the metadata is collected. The title and tags are used as input in text-based query analysis to determine the relevance of a photo. Both fields contain information added by Flickr users about the description of the uploaded photo. Photos that are not related to Borobudur Temple Compound or tourism activities in the vicinity will not be used in spatial analysis. For instance, photos with a generic name usually certain prefix such as DSC (Digital Still Camera) and IMG (Image) were not used in this study. On the other hand, the following keywords were employed as a tourism activity identifier, namely Borobudur, Tourism, Holiday, Mendut, Heritage, Temple, and Relief. Photos that occupy the same coordinate were also removed.

\subsection{Density Analysis}

General spatial distribution identified by using quadrat density, since it can give a more rigid density picture, with the advantage of displaying the original distribution. The grid size used for calculating quadrat density is $30 \mathrm{~m}$, considering an analysis scale of 1: 60,000 (Figure 3). The number of points on each grid is calculated and saved in the attribute data of each grid. Visualization using the standard deviation classification system is used to display maps. Grids with an amount of data 1 will be excluded in this visualization to reduce the complexity of the map display.

The number of point data in each grid can be a representation of tourism activity in the study area, especially photography. The approach used in this study does not consider the number of points on the neighboring grid since the photoshoot activity is specific to a distinct spot. High concentration of point data can be assumed as a favorite spot for a photo shoot at the study site, especially in the Borobudur Temple Compound. 


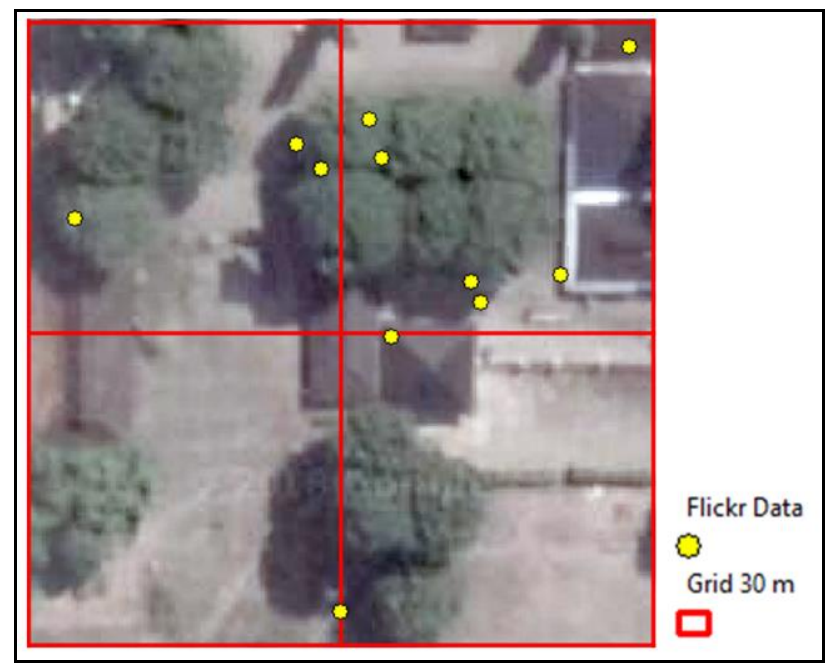

Figure 3. Example of quadrat density calulation

\subsection{Spatiotemporal Analysis}

Hotspot Analysis utilizes vector data to identify the location of hot spots and cold points that are statistically significant in the data used. In practice, the event points will be collected into a polygon or convergent point that is close to each other based on distance calculations [12]. Polygon groups/clusters will be arranged according to the values at each point and are classified as high (hot) or low (cold). The polygons can be either administrative boundaries or tessellation polygons.

The spatiotemporal analysis is carried out to determine the pattern of tourist activity both in the spatial and the specified period. Space-time cube is used for this analysis because it can reveal data patterns spatially. In principle, the space-time cube will aggregate point data into space-time bins. The bin has a three-dimensional structure, which spatially occupies the $\mathrm{x}$ and $\mathrm{y}$ positions, while the $\mathrm{z}$-axis represents time. In this study, the period for each bin is one month.

Visualization of space-time cube in 2 dimensions was done to find out the tendency of data, whether there is an up or down tendency. Getis-Ord Gi* was used to distinguish the structure of the level of cluster concentration [13]. More detailed analysis is performed using Emerging Hot Spot Analysis, which is used to break down trends into several categories namely new, consecutive, intensifying, persistent, diminishing, sporadic, oscillating, and historical hot and cold spots.

\section{RESULTS AND DISCUSSION}

\subsection{Flickr Data and Density Analysis}

The results of observations in the title and tag columns indicate a written error, even though they have the same purpose. For example, the user writes Borobudur with Borobadur, Borubadur, and Borabodur. These errors are tolerable and remain used in the data for spatiotemporal analysis. The filtering results gave 2,951 data that were relevant for the study, that number constituted $63.72 \%$ of the total data obtained at the study site.

There are three peaks when tourists take photos namely, $1 \mathrm{pm}, 4-5 \mathrm{pm}$, and $10 \mathrm{pm}$ (Figure 4). Among the three the $1 \mathrm{pm}$ peak have the highest number of photos and can be concluded as the favorite time for tourists to take pictures. Daytime is the peak of tourism activities in Borobudur. If the weather is not cloudy, visitors can take photos in the tourist area freely and get the maximum results. The second peak occurs at 4 to $5 \mathrm{am}$, during which time the sun is not too hot but with adequate lighting. These conditions are quite ideal for taking photos. The third peak occurs just before midnight, which is $10 \mathrm{pm}$. It can be inferred that most of these photos uploaded outside the Borobudur complex. 


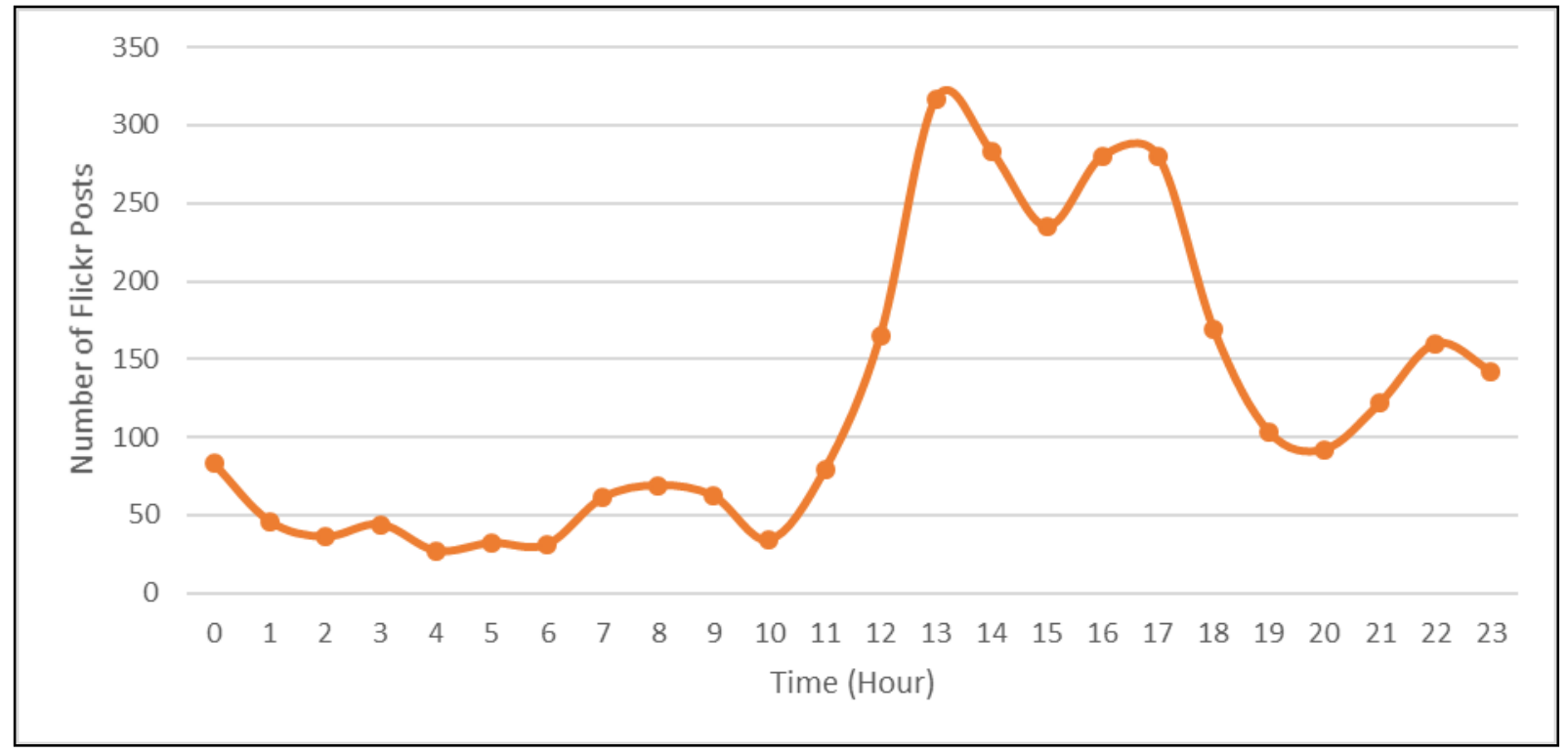

Figure 4. Temporal concentration of Flickr Data

Temporal analysis can reveal the favorite time of tourists in the study location. However, the information about the favorite location of tourists to take pictures is needed to formulate more specific planning. Quadrat Density analysis shows that in the area around Arupadhatu Stupa has the highest number of data (Figure 5). The Arupadhatu Stupa is located at the top of Borobudur Temple and the surrounding area has provided enough space to carry out photoshoots (Figure 6). The preservation of cultural heritage seen at Borobudur Temple is the prohibition to sit in the Stupa or touch the Stupa. The enforcement of the ban needs to be promoted especially in locations with high-density levels.

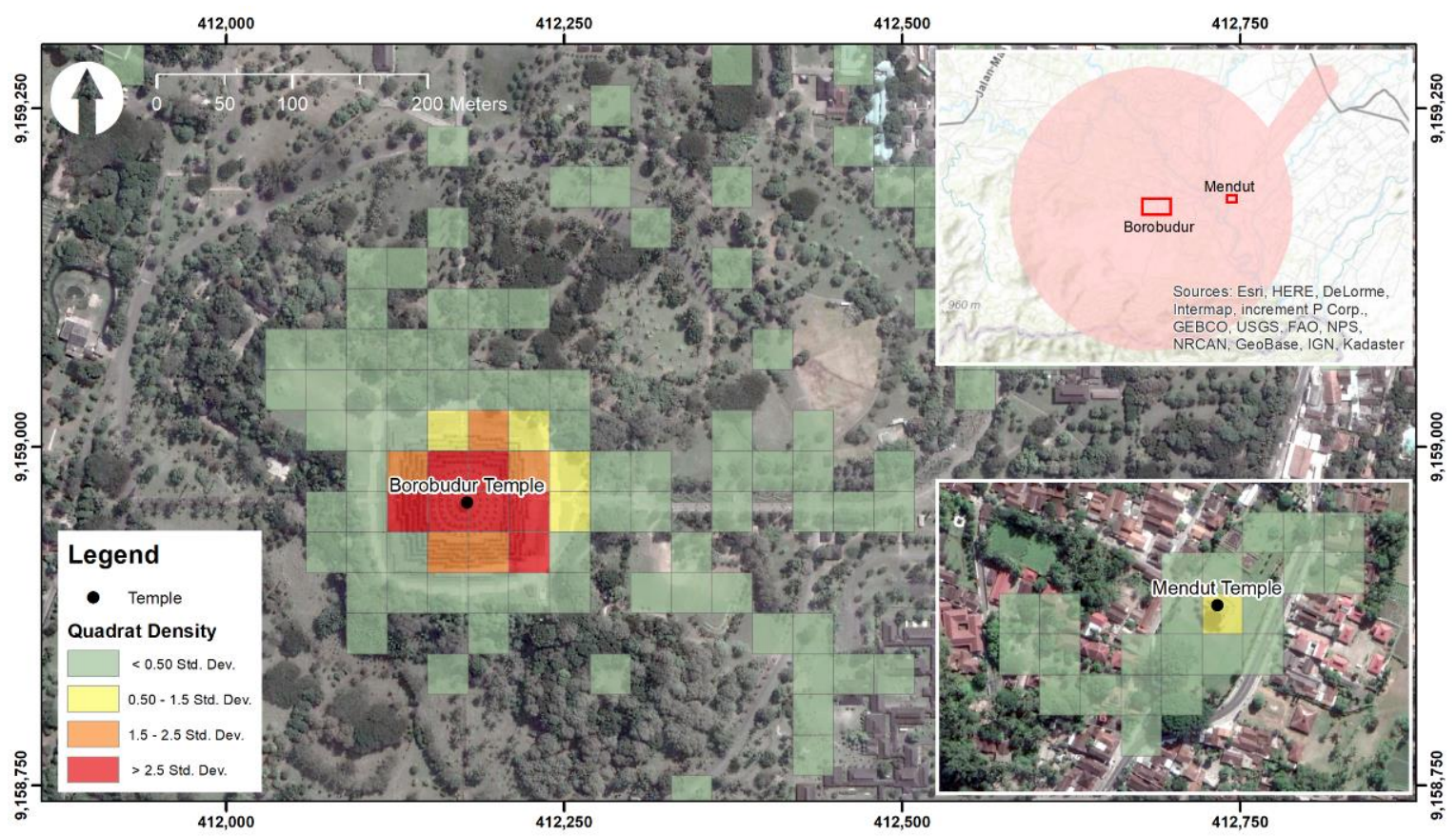

Figure 5. Quadrat density of Flickr data

The second-density level can be found on the eastern and southern sides of Borobudur Temple. The eastern part is the entry for tourist to the Borobudur Temple. The scene also seems photogenic because of the existence of Menoreh hills in 
the background. The existence of photography services that often offer their services at this location add opportunities for many photography activities.

Mendut Temple becomes the only location other than Borobudur Temple compound that has a significant density. There are 23 photos on the grid at Mendut Temple or 10 times smaller than the maximum number in a grid. A total of 1,034 grids (98\%) have less than 20 photos, which in this case is not significant. This vast difference shows that the appeal of photography in the study area is indeed located around the Borobudur Temple.

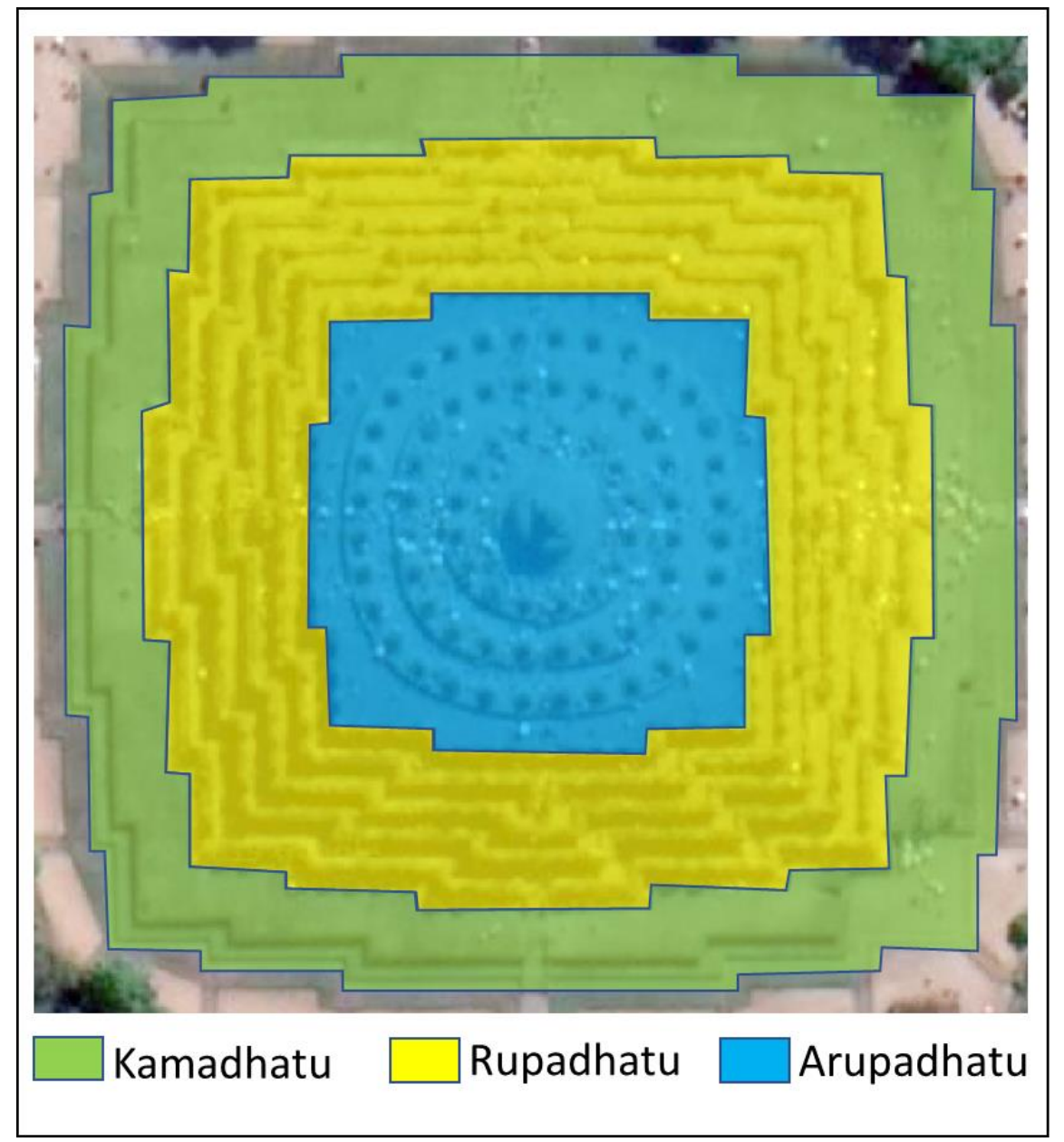

Figure 6. Three divisions of Borobudur Temple sturcture

\subsection{Borobudur Hot Spot Map}

In the previous section, we have discussed how the pattern of Flickr distribution data both temporally and spatially. Hot spots analysis in Figure 7 presents the results in the form of hot spots and cold spots around the Borobudur Compound Temple. The analysis revealed there were 11 varieties, 6 of which were categorized as cold spots. Meanwhile, there are four hot spot classes namely oscillating, sporadic, successive, and new hot spots. One other class is the data bin which is not significant either as a cold or hot spot.

Hot spots can be seen around Borobudur Temple and Mendut Temple. This result is supported by a significant quadrat density value. Slightly different results were found in the analysis of the hot spots that there were consecutive hot spots around the entrance of the temple courtyard. In the area near the Borobudur Temple Stupa classified as the oscillating hot spot category. Both results indicate that by the end of time-step there were plenty of photos taken around the entrance of the temple courtyard. On the other hand, located around the Stupa is a hot spot area that also being a statistically significant cold spot during earlier time-step. 


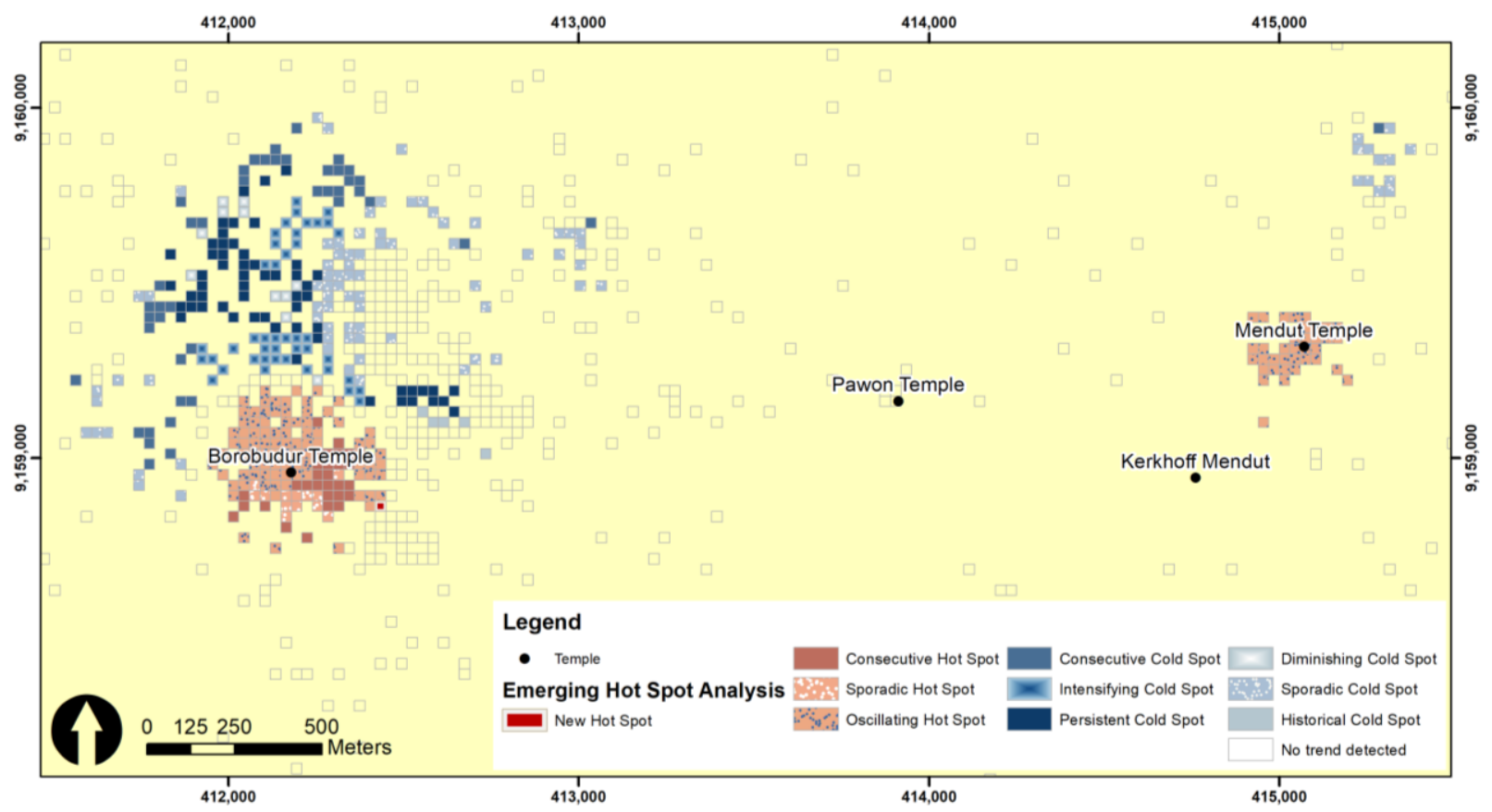

Figure 7. Hot spot analysis of Flickr geotagged data between 2005-2018

Areas with sporadic hot spot can be found in the southern part of Borobudur Temple. Statistically, this area has never been a cold spot but inconsistent for the specified period. This is interesting because the southern part of the temple has no attraction for tourists. After a tourist reaches the top of the temple, they will continue to move west and/or north of the temple. The pattern of the oscillating place formed also follows the direction of the tourist movement. Meanwhile, the pattern of the oscillating hot spot at Mendut Temple looks enclosing and uniform. There is no cold spot data that directly adjacent with that data. The Mendut temple complex which is not too broad can be easily reached by tourists.

Cold spots can be found in the northern part of Borobudur Temple, located outside the ring road. In that section, there are several interesting objects to visit such as elephants, Samudraraksa Museum, Borobudur Museum, Lumbini Park, and centers for crafts and food. Although these places have a high number of visiting visitors, only a small number of photos taken at these places will possibly be uploaded to social media accounts. This is because generally, the main purpose of Borobudur visitor is to see the temple and capture the moment there.

\section{CONCLUSION}

The results of the analysis show that there are a lot of photographic activities around the Stupa of Borobudur Temple. Hence, the preservation of the Borobudur Temple ideally should be concentrated around the Stupa. The eastern area of Borobudur Temple needs to be anticipated for development because based on hot spot data, the location is widely used for photography activities in recent years. Based on zoning data from JICA, the recommended area is included in the archeological environment preservation zone. Another area that also has quite a lot of photography activity is the Mendut Temple, which is part of the Borobudur Temple Compound. The temporal analysis shows the highest photography activity taken in the afternoon. Borobudur managers should ideally be able to use working hours to meet the needs of tourists for photography activity.

\section{ACKNOWLEDGEMENTS}

This work was completed as part of the 2019 Faculty of Geography UGM Lecturer Research Grant (2056.45/UN1/FGE/KPT/SETD/2019). 


\section{REFERENCES}

[1] F. Fischer, "VGI as big data. A new but delicate geographic data-source.," GeoInformatics, 2012.

[2] M. F. Goodchild, "Citizens as sensors: The world of volunteered geography," GeoJournal, vol. 69, no. 4, pp. 211-221, 2007.

[3] P. A. Longley, M. Adnan, and G. Lansley, "The Geotemporal Demographics of Twitter Usage," Environ. Plan. A, vol. 47, no. 2, pp. 465-484, 2015.

[4] J. A. Donaire, R. Camprubí, and N. Galí, “Tourist clusters from Flickr travel photography,” Tour. Manag. Perspect., 2014.

[5] A. Majid, L. Chen, G. Chen, H. T. Mirza, I. Hussain, and J. Woodward, "A context-aware personalized travel recommendation system based on geotagged social media data mining," Int. J. Geogr. Inf. Sci., vol. 27, no. 4, pp. 662-684, Apr. 2013.

[6] A. Majid, L. Chen, H. T. Mirza, I. Hussain, and G. Chen, "A system for mining interesting tourist locations and travel sequences from public geo-tagged photos," Data Knowl. Eng., vol. 95, pp. 66-86, Jan. 2015.

[7] S. Kisilevich, M. Krstajic, D. Keim, N. Andrienko, and G. Andrienko, "Event-based analysis of people's activities and behavior using Flickr and Panoramio geotagged photo collections," Proc. Int. Conf. Inf. Vis., pp. 289-296, 2010.

[8] L. Yang, L. Wu, Y. Liu, and C. Kang, "Quantifying tourist behavior patterns by travel motifs and geo-tagged photos from flickr," ISPRS Int. J. Geo-Information, vol. 6, no. 11, pp. 1-18, 2017.

[9] R. Ji, Y. Gao, B. Zhong, H. Yao, and Q. Tian, "Mining Flickr landmarks by modeling reconstruction sparsity," ACM Trans. Multimed. Comput. Commun. Appl., vol. 7 S, no. 1, 2011.

[10] Dinas Pariwisata Jawa Tengah, Buku Statistik Pariwisata Jawa Tengah 2017. 2017.

[11] F. D. Ekarini, "The Landscape of Borobudur Temple Compounds and its Environment," J. World Herit. Stud., vol. Special Is, pp. 24-29, 2017.

[12] D. O’Sullivan and D. J. Unwin, Geographic Information Analysis: Second Edition. 2010.

[13] U. R. R. Manepalli, G. H. Bham, and S. Kandada, "Evaluation of Hotspots Identification Using Kernel Density Estimation (K) and Getis-Ord (Gi*) on I-630," 3rd Int. Conf. Road Saf. Simul., 2011. 